\title{
(6) OPEN ACCESS \\ Comorbidities in patients with gout prior to and following diagnosis: case-control study
}

\author{
Chang-Fu Kuo, ${ }^{1,2}$ Matthew J Grainge, ${ }^{3}$ Christian Mallen, ${ }^{4}$ Weiya Zhang, ${ }^{1}$ \\ Michael Doherty ${ }^{1}$
}

\begin{abstract}
Handling editor Tore K Kvien
- Additional material is published online only. To view please visit the journal online (http://dx.doi.org/10.1136/ annrheumdis-2014-206410)

'Division of Rheumatology, Orthopaedics and Dermatology, School of Medicine, University of Nottingham, Nottingham, UK

${ }^{2}$ Division of Rheumatology, Allergy and Immunology, Chang Gung Memorial Hospital, Taoyuan, Taiwan ${ }^{3}$ Division of Epidemiology and Public Health, School of Medicine, University of Nottingham, Nottingham, UK ${ }^{4}$ Arthritis Research UK Primary Care Centre, Keele University, Keele, UK
\end{abstract}

\section{Correspondence to} Dr Weiya Zhang, Academic Rheumatology, Clinical Sciences Building, City Hospital, Nottingham NG51PB, UK: weiya.zhang@nottingham.ac.uk

Joint senior authors: WZ and MD.

Received 4 August 2014 Revised 13 October 2014 Accepted 26 October 2014 Published Online First 14 November 2014

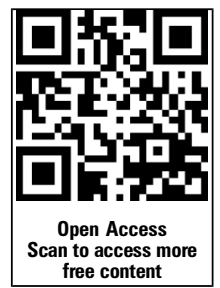

CrossMark

To cite: Kuo C-F,

Grainge MJ, Mallen C, et al. Ann Rheum Dis

2016:75:210-217.

\section{ABSTRACT}

Objectives To determine the burden of comorbidities in patients with gout at diagnosis and the risk of developing new comorbidities post diagnosis.

Methods There were 39111 patients with incident gout and 39111 matched controls identified from the UK Clinical Practice Research Data-link. The risk of comorbidity before (ORs) and after the diagnosis of gout (HRs) were estimated, adjusted for age, sex, diagnosis year, body mass index, smoking and alcohol consumption.

Results Gout was associated with adjusted ORs (95\% Cls) of 1.39 (1.34 to 1.45), 1.89 (1.76 to 2.03) and 2.51 (2.19 to 2.86) for the Charlson index of $1-2,3-4$ and $\geq 5$, respectively. Cardiovascular and genitourinary diseases, in addition to hyperlipidaemia, hypothyroidism, anaemia, psoriasis, chronic pulmonary diseases, osteoarthritis and depression, were associated with a higher risk for gout. Gout was also associated with an adjusted HR $(95 \% \mathrm{CI})$ of 1.41 (1.34 to 1.48) for having a Charlson index $\geq 1$. Median time to first comorbidity was 43 months in cases and 111 months in controls. Risks for incident comorbidity were higher in cardiovascular, genitourinary, metabolic/ endocrine and musculoskeletal diseases, in addition to liver diseases, hemiplegia, depression, anaemia and psoriasis in patients with gout. After additionally adjusting for all comorbidities at diagnosis, gout was associated with a HR $(95 \% \mathrm{Cl})$ for all-cause mortality of 1.13 (1.08 to 1.18 ; $\mathrm{p}<0.001)$.

Conclusions The majority of patients with gout have worse pre-existing health status at diagnosis and the risk of incident comorbidity continues to rise following diagnosis. The range of associated comorbidities is broader than previously recognised and merits further evaluation.

\section{INTRODUCTION}

Gout is the most common inflammatory arthritis worldwide with a recent estimated prevalence of $2.49 \%$ in the UK. ${ }^{1}$ Initial presentation is usually with acute arthritis but chronic joint damage, subcutaneous tophi and periarticular inflammation are other common manifestations. ${ }^{2}$ Since gout results from chronic hyperuricaemia and the deposition of urate crystals, urate-lowering treatment (ULT) capable of preventing crystal formation and dissolving existing crystal deposits may potentially 'cure' gout. ${ }^{3}$ Gout is also associated with comorbidities that may impair well-being and reduce longevity. ${ }^{4-6}$ It is generally accepted that gout is highly associated with the features of metabolic syndrome, ${ }^{7}$ nephrolithiasis ${ }^{8} 9$ and chronic renal impairment. ${ }^{10}$ However, suggested associations with other cardiovascular disease ${ }^{6} 11-14$ is controversial, ${ }^{15}$ and there is only limited evidence for possible associations with cancer, ${ }^{16}{ }^{17}$ hypothyroidism ${ }^{1819}$ and anaemia. ${ }^{20}$

Current clinical guidelines and recommendations endorsed by the European League against Rheumatism, ${ }^{21}$ American College of Rheumatology ${ }^{22}$ and British Society for Rheumatology/British Health Professionals in Rheumatology ${ }^{23}$ agree on the importance of comorbidity on gout management but only discuss diseases that are recognised to be pathophysiologically related to gout. In addition, ULT is generally recommended only for patients with high urate load or with comorbidities such as poor kidney function. Although a focus on comorbidities that are causally related to or are seen as complications of gout is understandable, many patients with gout are 'complicated' by multiple comorbidities that may or may not be related directly to gout and management decisions in such cases are often difficult since recommendations and guidelines give no specific guidance in these scenarios.

Although comorbidity is considered to be epidemic in gout ${ }^{24-26}$ previous studies have only included limited categories of comorbidities. In addition, the timing of comorbidity occurrence relative to gout diagnosis has not been addressed. Therefore, using data representative of the general population of UK from the Clinical Practice Research Data-link (CPRD), this study aimed to examine the burden of comorbidity at the time of first diagnosis of gout compared with matched controls. We further followed patients with incident gout and their matched controls after diagnosis to compare their subsequent accumulation of comorbidities and all-cause mortality.

\section{METHODS}

This was a case-control study using retrospective data (prior to diagnosis) and subsequent follow-up data (after diagnosis) within the CPRD. We hypothesised that gout has a higher burden of comorbidity at the time of first diagnosis and that the risk of comorbidity would continue to rise after the diagnosis of the disease. The study was approved by the Independent Scientific Advisory Committee for Medicines and Healthcare Products Regulatory Agency (MHRA) Database Research (protocol 11-021R).

\section{Data source}

The CPRD is a database containing prospectively collected medical records of research standard from around 12 million individuals in the UK. The database has been described previously ${ }^{27}$ and has been 
validated for many diagnoses, including gout and comorbid conditions under scrutiny in this study. ${ }^{28-32}$ The database contains comprehensive information on patient demographics, lifestyle factors, medical diagnoses, results of investigations and examinations and prescribed medications. The CPRD is also linked to additional data sources including secondary care, Office for National Statistics cause of death data and information from specific disease registries.

\section{Definition of incident gout}

We used Read codes (a standard clinical terminology system used in general practice in the UK originally developed by Dr James Read) to identify patients with incident gout from the CPRD between 1997 and 2005. To be eligible as a patient with incident gout, participants had to have no evidence of gout and no prescription for ULT prior to the time of diagnosis (index date) and to have at least a 3-year continuous registration prior to the index date. ${ }^{33}$ The case definition was based on physiciandiagnosis using 18 Read codes indicative of incident gout. ${ }^{1}$ The diagnosis of gout in the CPRD has been validated previously by a review of medical records of 10 patients with confirmed and 28 patients with probable gout showing that 10 out of 10 confirmed cases and 24 out of 28 probable cases were true gout (overall ascertainment rate $90 \%$ ). ${ }^{32}$

\section{Selection of controls}

From CPRD participants who had an active registration from 1997 to 2005, we identified at random one control per case who had no record of gout and no prescriptions of ULT in the CPRD. Control patients were frequency-matched in a $1: 1$ ratio to patients with incident gout by year of birth ( \pm 2 years), gender, general practice and year of first continuous registration ( \pm 2 years) at this CPRD practice. The same index date was assigned to each of the matched controls. As with patients with incident gout the matched controls had at least 3 years of registration prior to the index date.

\section{Study period}

We defined three periods to assess comorbidity: (A) the 10 years prior to diagnosis; (B) the 1 year prior to diagnosis; and $(\mathrm{C})$ from diagnosis to the earliest date of occurrence of comorbidity, death, transfer out or end of study (31 December 2013), whichever came first. Cumulative probability of comorbidity was estimated at the time of diagnosis (index date) as well as 1 year, 2 years, 5 years and 10 years following diagnosis.

\section{Comorbidity of interest and mortality}

We defined gout as the index disease in this study and used Feinstein's definition for comorbidity, specifically: "Any distinct additional entity that has existed or may occur during the clinical course of a patient who has the index disease under study." 34 General health status was measured by the Charlson comorbidity index. The index summarises 17 diagnostic categories (myocardial infarction, congestive heart failure, peripheral vascular disease, cerebrovascular disease, dementia, chronic pulmonary disease, rheumatological disease, peptic ulcer disease, mild liver disease, moderate or severe liver disease, diabetes mellitus (DM), DM with chronic complications, renal diseases, any malignancy (including leukaemia and lymphoma), metastatic solid tumour and HIV infection) to represent one's health status and has been a useful predictor for mortality. ${ }^{35}$ Deyo et $a l^{36}$ produced a validated version for use with the International Classification of Diseases, Ninth Revision (ICD-9) based database, which was the basis of the validated Read code version. ${ }^{37}$ We calculated the Charlson score for each study person at baseline by adding scores assigned to each specific diagnosis. In addition, we also incorporated other comorbidities potentially associated with gout, including anaemia, cardiac arrhythmias, depression, hypertension, hypothyroidism, multiple sclerosis, neurological diseases, osteoarthritis, psoriasis, psychosis, urolithiasis and valvular heart disease (please refer to supplement for the rationale in selection of these comorbidities). All comorbidities were further categorised into eight categories according to systems. The definitions of these conditions were also based on physician diagnoses recorded as Read codes. We identified patients with these comorbidities from records within each of the three study periods as stated above. The Charlson index at diagnosis was based on results from the 10 -year period. We categorised Charlson index as (1) $0,1-2,3-$ 4 and $\geq 5$ scores and (2) dichotomised it as 0 and $\geq 1$ score. Mortality was based on the recording in the main database. We undertook a validation study and found the sensitivity, specificity, positive predictive value and negative predictive value of a CPRD recorded death were $0.99,0.99,0.93$ and 1.00 , respectively, suggesting that the recording of death in the CPRD is generally consistent with death registration (details in online supplement and table S1).

\section{Statistical analysis}

The prevalence of a specific comorbidity was calculated using the number of people ever diagnosed with a given comorbidity during the past 10-year period or 1-year period before the index date as the numerator and the number of patients with incident gout or matched controls as denominators. ORs and 95\% CIs were used to estimate the association between gout and each coexisting medical condition. Conditional logistic regression was used to adjust for age, gender, index year, body mass index (BMI) category, smoking status and alcohol consumption. Missing data for BMI, smoking and alcohol status were coded as 'unknown'. Kaplan-Meier plots were used to estimate the cumulative probability of each comorbidity and allcause mortality in people with incident gout and those without. For calculation of cumulative probabilities, the first percentage (at baseline), indicates the percentage of people with a diagnosis before the index date. Only people at risk for a given comorbidity (not having such comorbidity at index date) were considered to estimate HRs of a specific comorbidity. HRs with 95\% CIs were calculated for a Charlson index $\geq 1$, for each comorbidity separately and all-cause mortality using a Cox proportional hazards model. The HRs were adjusted by age, gender, index year, BMI categories, smoking status and alcohol consumption. For all-cause mortality we also adjusted for all categories of comorbidities at baseline. All statistical analyses were performed using SAS statistical software, V.9.3.

\section{RESULTS}

We identified 39111 patients with incident gout during 1997 to 2005 with a mean age of $62.2 \pm 15.1$ years and $72.49 \%$ being men. The median observation periods (interquartile range; IQR) before and after index date were 15 (9-27) and 9 (5-11) years, respectively. They were 1:1 matched to 39111 controls with the same age and sex structure and observation periods before and after index date (table 1). The odds of gout increased significantly with BMI, alcohol consumption and smoking.

\section{Retrospective observation}

At the time of index date, the proportion of people having at least one comorbidity listed in the Charlson index was 
Table 1 Characteristics of patients with incident gout and controls. Values are numbers (percentages) unless stated otherwise

\begin{tabular}{|c|c|c|c|}
\hline & $\begin{array}{l}\text { Incident gout } \\
\text { ( } n=39111)\end{array}$ & $\begin{array}{l}\text { Controls } \\
(n=39111)\end{array}$ & $\begin{array}{l}\text { Adjusted ORs } \\
(95 \% \mathrm{Cl})\end{array}$ \\
\hline \multicolumn{4}{|l|}{ Age (years) } \\
\hline$<50$ & 8661 (22.14) & $8709(22.27)$ & $\mathrm{N} / \mathrm{A}$ \\
\hline $50-59$ & 7815 (19.98) & $7822(20.00)$ & $\mathrm{N} / \mathrm{A}$ \\
\hline $60-69$ & $8586(21.95)$ & $8608(22.01)$ & $\mathrm{N} / \mathrm{A}$ \\
\hline$\geq 70$ & 14049 (35.92) & 13972 (35.72) & $\mathrm{N} / \mathrm{A}$ \\
\hline \multicolumn{4}{|l|}{ Gender } \\
\hline Men & 28350 (72.49) & 28350 (72.49) & $\mathrm{N} / \mathrm{A}$ \\
\hline Women & $10761(27.51)$ & $10761(27.51)$ & N/A \\
\hline \multicolumn{4}{|c|}{ Median observation years (IQR) } \\
\hline Prior to index date & $15(9-27)$ & $15(9-27)$ & $\mathrm{N} / \mathrm{A}$ \\
\hline After index date & $9(5-11)$ & $9(5-11)$ & $\mathrm{N} / \mathrm{A}$ \\
\hline \multicolumn{4}{|l|}{ BMI $\left(\mathrm{kg} / \mathrm{m}^{2}\right)$} \\
\hline$<18.5$ & $261(0.67)$ & $564(1.44)$ & $0.66(0.56-0.77)^{*}$ \\
\hline $18.5-24.9$ & $7894(20.18)$ & $11734(30.00)$ & Reference \\
\hline $25.0-29.9$ & 15206 (38.88) & 12815 (32.77) & $1.81(1.74-1.88)^{*}$ \\
\hline$\geq 30$ & 12199 (31.19) & $6076(15.54)$ & $3.15(3.01-3.30)^{*}$ \\
\hline Unknown & $3551(9.08)$ & 7922 (20.26) & $0.60(0.57-0.63)^{*}$ \\
\hline \multicolumn{4}{|l|}{ Smoking } \\
\hline Non-smoker & $10315(26.37)$ & 8835 (22.59) & Reference \\
\hline Current smoker & $5783(14.79)$ & $4233(10.82)$ & $1.22(1.16-1.29)^{*}$ \\
\hline Ex-smoker & 18269 (46.71) & $17136(43.81)$ & $0.87(0.83-0.90)^{*}$ \\
\hline Unknown & $4744(12.13)$ & 8907 (22.77) & $0.39(0.37-0.41)^{*}$ \\
\hline \multicolumn{4}{|c|}{ Alcohol consumption (units/week) } \\
\hline Never/Ex-drinker & 4051 (10.36) & 4338 (11.09) & Reference \\
\hline Current 1-9 & $17410(44.51)$ & $17123(43.78)$ & $1.14(1.09-1.20)^{*}$ \\
\hline Current $\geq 10$ & $10285(26.30)$ & $5801(14.83)$ & $2.14(2.02-2.27)^{*}$ \\
\hline Unknown & $7365(18.83)$ & $11849(30.30)$ & $0.63(0.60-0.67)^{*}$ \\
\hline
\end{tabular}

significantly higher in patients with incident gout $(32.25 \%)$ than in controls $(27.97 \% ; \mathrm{p}<0.001)$. In an adjusted logistic regression model in the 10-year period before the index date, ORs $(95 \%$ CIs) were 1.39 (1.34 to 1.45$), 1.89$ (1.76 to 2.03 ) and 2.51 (2.19 to 2.86 ) for Charlson scores $1-2,3-4$ and $\geq 5$ ( $p_{\text {trend }}<0.001$ ), respectively. The analysis restricted to diagnoses recorded in the 1 -year period prior to the index date gave a similar magnitude of effects (see online supplementary table S2).

All cardiovascular and genitourinary diseases were associated with a higher risk for incident gout, the highest risk being for renal diseases (OR, 5.96) and congestive heart disease (OR, 4.37) (see online supplementary table S2). In addition, hyperlipidaemia (OR 1.71), hypothyroidism (OR 1.50), anaemia (OR 1.40 ), psoriasis (OR 1.32), chronic pulmonary diseases (OR 1.30), osteoarthritis (OR 1.27) and depression (OR 1.09) also positively associated with incident gout in adjusted models in the 10-year and 1-year periods, while dementia (OR 0.54), multiple sclerosis (OR 0.61) and other neurological diseases (OR 0.83 ) were negatively associated with incident gout. Interestingly, uncomplicated DM and complicated DM were not significant risk factors for incident gout, even showing a slight negative association in logistic regression models.

\section{Follow-up data after index date}

Overall, median time to first comorbidity in the Charlson index was 43 months (95\% CI 41 months to 45 months) in patients
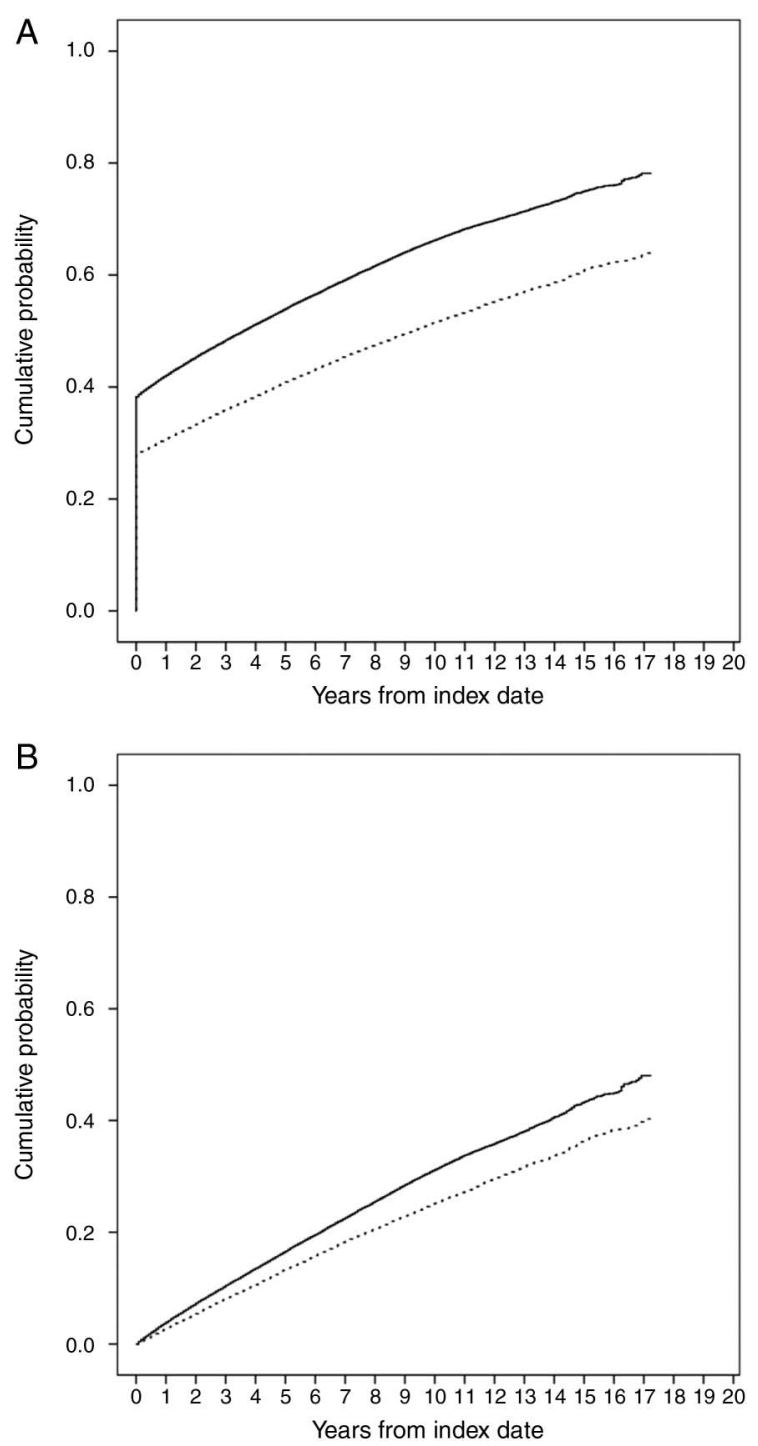

Figure 1 Cumulative probability of $(A)$ having the first comorbidity in the categories of Charlson index (B) an increase in the score of Charlson index in patients with incident gout (solid line) and matched controls (dotted line).

with incident gout and 111 months (95\% CI 108 months to 115 months) in controls (log-rank test $\mathrm{p}<0.001)$. The cumulative probability of having the first comorbidity in the Charlson index at 1 year, 2 years, 5 years and 10 years from index date were, respectively, $42.09 \%, 45.39 \%, 53.99 \%$ and $66.28 \%$ in patients with incident gout and 30.78\%, 33.32\%, 40.92\% and $51.54 \%$ in controls (figure 1A). In addition, the cumulative probability of any increase in Charlson score was significantly greater in patients with gout than in controls at all time points after diagnosis (log-rank test, $\mathrm{p}<0.001$; figure $1 \mathrm{~B}$ ). Table 2 shows cumulative probabilities for specific comorbidities (including existing and new ones) in patients with incident gout and matched controls at index date and 1 year, 2 years, 5 years and 10 years after index date. It is apparent that cumulative risks of most categories of comorbidity after index date were higher in patients with gout than in matched controls.

Next we investigated relative risk of incident comorbidity. Among people with a Charlson score of zero at index date, gout associated with adjusted HRs (95\% CI) of 1.41 (1.34 to 1.48) for having a Charlson index $\geq 1$. Furthermore, risk of 
Table 2 Cumulative probability of comorbidity after diagnosis of gout

\begin{tabular}{|c|c|c|c|c|c|c|c|c|c|c|c|}
\hline & \multicolumn{5}{|c|}{ Patients with incident gout } & \multicolumn{5}{|l|}{ Controls } & \multirow[b]{2}{*}{ p Value } \\
\hline & At diagnosis & 1 year & 2 years & 5 years & 10 years & At diagnosis & 1 year & 2 years & 5 years & 10 years & \\
\hline Charlson index $\geq 1$ & 38.25 & 42.09 & 45.39 & 53.99 & 66.27 & 27.97 & 30.78 & 33.32 & 40.91 & 51.54 & $<0.001$ \\
\hline Any increase in Charlson index & 0 & 3.88 & 7.30 & 16.60 & 31.19 & 0 & 3.80 & 6.95 & 14.54 & 23.24 & $<0.001$ \\
\hline \multicolumn{12}{|l|}{ Neoplasms } \\
\hline Solid malignancy, leukaemia and lymphoma & 5.35 & 6.47 & 7.76 & 11.84 & 19.44 & 4.49 & 5.54 & 6.56 & 10.27 & 16.76 & $<0.001$ \\
\hline Metastatic solid tumours & 0.14 & 0.30 & 0.51 & 1.05 & 2.08 & 0.16 & 0.33 & 0.49 & 0.97 & 1.88 & 0.266 \\
\hline \multicolumn{12}{|l|}{ Cardiovascular diseases } \\
\hline Hypertension & 34.81 & 38.46 & 41.58 & 49.62 & 59.64 & 18.70 & 21.28 & 23.85 & 30.50 & 39.19 & $<0.001$ \\
\hline Cardiac arrhythmias & 8.80 & 9.93 & 11.00 & 14.01 & 19.10 & 3.72 & 4.30 & 5.02 & 6.95 & 10.64 & $<0.001$ \\
\hline Cerebrovascular disease & 5.99 & 7.02 & 7.95 & 10.46 & 14.48 & 4.13 & 4.92 & 5.57 & 7.65 & 10.74 & $<0.001$ \\
\hline Congestive heart failure & 8.54 & 9.49 & 10.30 & 12.04 & 14.59 & 2.35 & 2.87 & 3.28 & 4.37 & 6.03 & $<0.001$ \\
\hline Myocardial infarction & 5.47 & 6.12 & 6.63 & 8.15 & 10.54 & 2.76 & 3.23 & 3.57 & 4.86 & 6.87 & $<0.001$ \\
\hline Peripheral vascular disease & 3.85 & 4.43 & 4.93 & 6.23 & 8.35 & 2.36 & 2.65 & 2.92 & 3.92 & 5.49 & $<0.001$ \\
\hline Valvular heart disease & 2.27 & 2.60 & 2.96 & 3.94 & 5.71 & 0.96 & 1.12 & 1.29 & 1.78 & 2.87 & $<0.001$ \\
\hline \multicolumn{12}{|l|}{ Genitourinary diseases } \\
\hline Urolithiasis & 0.94 & 1.05 & 1.14 & 1.42 & 1.99 & 0.66 & 0.73 & 0.82 & 1.07 & 1.42 & $<0.001$ \\
\hline Renal diseases & 3.05 & 4.20 & 5.30 & 8.50 & 12.51 & 0.54 & 0.76 & 1.07 & 2.22 & 4.04 & $<0.001$ \\
\hline \multicolumn{12}{|l|}{ Metabolic and endocrine diseases } \\
\hline Uncomplicated diabetes mellitus & 7.08 & 8.37 & 9.66 & 13.87 & 20.87 & 5.83 & 6.46 & 7.11 & 9.21 & 12.50 & $<0.001$ \\
\hline Diabetes mellitus with complications & 1.30 & 1.64 & 2.03 & 3.60 & 13.92 & 1.13 & 1.43 & 1.71 & 2.79 & 8.41 & $<0.001$ \\
\hline Hyperlipidaemia & 10.11 & 11.75 & 13.23 & 17.10 & 22.05 & 5.37 & 6.30 & 7.28 & 10.04 & 13.94 & $<0.001$ \\
\hline Hypothyroidism & 3.61 & 4.15 & 4.68 & 6.22 & 8.29 & 2.23 & 2.60 & 2.95 & 4.03 & 5.58 & $<0.001$ \\
\hline \multicolumn{12}{|l|}{ Gastrointestinal and hepatic diseases } \\
\hline Peptic ulcer disease & 2.02 & 2.33 & 2.54 & 3.10 & 3.88 & 1.78 & 1.96 & 2.11 & 2.50 & 3.14 & $<0.001$ \\
\hline Mild liver disease & 0.39 & 0.52 & 0.62 & 1.11 & 1.99 & 0.29 & 0.35 & 0.40 & 0.60 & 0.94 & $<0.001$ \\
\hline Moderate to severe liver disease & 0.08 & 0.10 & 0.11 & 0.21 & 0.43 & 0.07 & 0.08 & 0.10 & 0.18 & 0.30 & 0.002 \\
\hline Chronic pulmonary diseases & 13.59 & 14.70 & 15.62 & 18.20 & 22.02 & 9.83 & 10.57 & 1.44 & 13.66 & 17.15 & $<0.001$ \\
\hline \multicolumn{12}{|l|}{ Musculoskeletal and connective tissue diseases } \\
\hline Osteoarthritis & 10.91 & 12.71 & 14.24 & 18.30 & 24.00 & 7.80 & 8.83 & 9.77 & 12.47 & 16.55 & $<0.001$ \\
\hline Rheumatological disease & 7.12 & 8.46 & 9.72 & 12.94 & 18.78 & 6.12 & 6.77 & 7.37 & 9.22 & 12.31 & $<0.001$ \\
\hline \multicolumn{12}{|l|}{ Neurological and mental disorders } \\
\hline Dementia & 0.30 & 0.46 & 0.65 & 1.29 & 2.97 & 0.56 & 0.79 & 1.02 & 1.79 & 3.76 & $<0.001$ \\
\hline Hemiplegia & 0.39 & 0.48 & 0.55 & 0.6 & 1.03 & 0.37 & 0.44 & 0.46 & 0.64 & 0.80 & 0.007 \\
\hline Multiple sclerosis & 0.08 & 0.09 & 0.09 & 0.11 & 0.13 & 0.15 & 0.16 & 0.17 & 0.19 & 0.23 & 0.003 \\
\hline Other neurological diseases & 1.77 & 2.17 & 2.53 & 3.62 & 5.30 & 2.17 & 2.51 & 2.84 & 3.84 & 5.65 & 0.071 \\
\hline Psychosis & 0.40 & 0.49 & 0.55 & 0.75 & 1.16 & 0.24 & 0.61 & 0.68 & 0.93 & 1.27 & 0.234 \\
\hline Depression & 12.10 & 13.60 & 14.97 & 18.90 & 24.74 & 10.39 & 11.45 & 12.59 & 15.76 & 20.59 & $<0.001$ \\
\hline \multicolumn{12}{|l|}{ Other comorbidities } \\
\hline Anaemia & 8.84 & 1.45 & 11.75 & 16.11 & 23.43 & 5.86 & 6.68 & 7.55 & 10.43 & 15.55 & $<0.001$ \\
\hline Psoriasis & 3.20 & 3.53 & 3.81 & 4.63 & 5.81 & 2.24 & 2.40 & 2.61 & 3.12 & 3.85 & $<0.001$ \\
\hline HIV infection & 0.03 & 0.03 & 0.04 & 0.04 & - & $<0.001$ & - & - & 0.03 & - & 0.027 \\
\hline
\end{tabular}

developing incident comorbidity in the categories of cardiovascular, genitourinary, metabolic/endocrine and musculoskeletal/ connective tissue diseases was higher in patients with gout (table 3 ). For example, patients with gout were three times more likely to develop renal diseases (HR 3.18, 95\% CI 2.88 to 3.50 ). In addition, risks of liver diseases, hemiplegia, depression, anaemia and psoriasis were also higher in patients with gout. In contrast, patients with gout were less likely (HR 0.82 , 95\% CI 0.73 to 0.92 ) to have dementia.

After index date, mortality at 5 years and 10 years (95\% CIs) from any cause was $14.43 \%$ and $26.98 \%$ in patients with incident gout, compared with $11.14 \%$ and $21.66 \%$ in matched controls (log-rank test, $\mathrm{p}<0.001$; see online supplementary table S3). In men and women estimates of the effect of a gout diagnosis on mortality were attenuated after adjustment for demographic and lifestyle variables (model 2), and attenuated even further after adjustment for comorbidity status at index date (model 3) (see online supplementary table S4). After the adjustment for age, sex, index year, BMI class, smoking status, alcohol consumption and all individual comorbidities at diagnosis (model 3), gout associated with a HR $(95 \% \mathrm{CI}$ ) for all-cause mortality of 1.13 (1.08 to $1.18 ; \mathrm{p}<0.001)$.

\section{DISCUSSION}

This study used a large primary care database in the UK to compare the burden of existing comorbidity at diagnosis in patients with gout with matched controls and to estimate the risks of developing new comorbidities following diagnosis. Overall, a third of patients with newly diagnosed gout already had a Charlson score $\geq 1$, compared with a quarter of matched controls. The prevalence of hypertension, cardiac arrhythmias, valvular heart disease, urolithiasis, hyperlipidaemia, 
Table 3 Risk of incident comorbidity after diagnosis of gout

\begin{tabular}{|c|c|c|c|c|}
\hline & At-risk cases & At-risk controls & Unadjusted HRs & Adjusted HRst \\
\hline All-cause mortality & $39111(25.40)$ & $39111(20.20)$ & $1.34(1.29-1.39)^{*}$ & $1.36(1.31-1.42)^{*}$ \\
\hline Charlson index $\geq 1$ & $24152(41.31)$ & $28171(29.40)$ & $1.62(1.55-1.70)^{*}$ & $1.41(1.34-1.48)^{*}$ \\
\hline Any increase in Charlson index & $39111(25.51)$ & $39111(21.18)$ & $1.31(1.26-1.36)^{*}$ & $1.20(1.16-1.26)^{*}$ \\
\hline \multicolumn{5}{|l|}{ Neoplasms } \\
\hline Solid malignancy, leukaemia and lymphoma & $37040(12.52)$ & 37375 (11.04) & $1.17(1.11-1.23)^{*}$ & $1.10(1.04-1.16)^{*}$ \\
\hline Metastatic solid tumours & $39057(1.57)$ & $39047(1.47)$ & $1.06(0.93-1.21)$ & $1.04(0.91-1.20)$ \\
\hline \multicolumn{5}{|l|}{ Cardiovascular diseases } \\
\hline Hypertension & $25496(31.47)$ & 31798 (21.21) & $1.83(1.74-1.92)^{*}$ & $1.51(1.43-1.58)^{*}$ \\
\hline Cardiac arrhythmias & $35669(9.60)$ & $37656(6.18)$ & $1.74(1.62-1.86)^{*}$ & $1.59(1.48-1.70)^{*}$ \\
\hline Cerebrovascular disease & $36767(7.74)$ & 37494 (5.99) & $1.38(1.29-1.47)^{*}$ & $1.29(1.62-1.86)^{*}$ \\
\hline Congestive heart failure & $35772(5.78)$ & $38192(3.25)$ & $2.01(1.84-2.18)^{*}$ & $1.81(1.65-1.98)^{*}$ \\
\hline Myocardial infarction & $36973(4.39)$ & $38032(3.52)$ & $1.25(1.14-1.37)^{*}$ & $1.16(1.05-1.28)^{*}$ \\
\hline Peripheral vascular disease & $37605(3.90)$ & $38189(2.62)$ & $1.58(1.44-1.74)^{*}$ & $1.56(1.40-1.72)^{*}$ \\
\hline Valvular heart disease & $38223(2.93)$ & $38735(1.64)$ & $1.96(1.76-2.19)^{*}$ & $1.80(1.60-2.04)^{*}$ \\
\hline \multicolumn{5}{|l|}{ Genitourinary diseases } \\
\hline Urolithiasis & $38743(0.84)$ & $38855(0.63)$ & $1.39(1.16-1.67)^{*}$ & $1.26(1.02-1.55)^{*}$ \\
\hline Renal diseases & $37919(8.00)$ & $38899(2.81)$ & $3.43(3.13-3.76)^{*}$ & $3.18(2.88-3.50)^{*}$ \\
\hline \multicolumn{5}{|l|}{ Metabolic and endocrine diseases } \\
\hline Uncomplicated diabetes mellitus & $36342(12.07)$ & $36832(5.94)$ & $2.15(2.02-2.29)^{*}$ & $1.65(1.54-1.77)^{*}$ \\
\hline Diabetes mellitus with complications & $38604(10.82)$ & $38669(6.29)$ & $1.80(1.70-1.92)^{*}$ & $1.35(1.26-1.45)^{*}$ \\
\hline Hyperlipidaemia & $35156(10.69)$ & $37011(7.30)$ & $1.64(1.54-1.75)^{*}$ & $1.40(1.31-1.50)^{*}$ \\
\hline Hypothyroidism & $37701(4.00)$ & $38237(2.81)$ & $1.53(1.40-1.68)^{*}$ & $1.46(1.32-1.61)^{*}$ \\
\hline \multicolumn{5}{|l|}{ Gastrointestinal and hepatic diseases } \\
\hline Peptic ulcer disease & $39079(0.29)$ & $39084(0.19)$ & $1.53(1.09-2.16)^{*}$ & $1.37(0.95-2.00)$ \\
\hline Mild liver disease & $38321(1.64)$ & $38416(1.12)$ & $1.52(1.32-1.75)^{*}$ & $1.47(1.26-1.72)^{*}$ \\
\hline Moderate to severe liver disease & $38960(1.26)$ & $38997(0.53)$ & $2.39(2.00-2.85)^{*}$ & $1.97(1.61-2.41)^{*}$ \\
\hline Chronic pulmonary diseases & $33795(8.11)$ & $35267(6.81)$ & $1.20(1.12-1.28)^{*}$ & $1.10(1.02-1.18)^{*}$ \\
\hline \multicolumn{5}{|l|}{ Musculoskeletal and connective tissue diseases } \\
\hline Osteoarthritis & $34843(12.10)$ & $36062(7.84)$ & $1.71(1.61-1.82)^{*}$ & $1.45(1.35-1.54)^{*}$ \\
\hline Rheumatological disease & $36325(10.43)$ & $36719(5.54)$ & $1.96(1.84-2.10)^{*}$ & $1.57(1.46-1.69)^{*}$ \\
\hline \multicolumn{5}{|l|}{ Neurological and mental disorders } \\
\hline Dementia & $38994(2.22)$ & $38892(2.63)$ & $0.83(0.75-0.93)^{*}$ & $0.82(0.73-0.92)^{*}$ \\
\hline Hemiplegia & $38959(0.51)$ & $38968(0.36)$ & $1.50(1.19-1.89)^{*}$ & $1.48(1.16-1.90)^{*}$ \\
\hline Multiple sclerosis & $39081(0.05)$ & $39053(0.06)$ & $0.70(0.37-1.30)$ & $0.70(0.22-2.18)$ \\
\hline Other neurological diseases & $38419(3.01)$ & 38261 (2.94) & $1.08(0.98-1.19)$ & $1.06(0.96-1.17)$ \\
\hline Psychosis & $38953(0.63)$ & $38901(0.60)$ & $1.00(0.81-1.23)$ & $1.04(0.82-1.32)$ \\
\hline Depression & $34379(11.93)$ & $35047(9.42)$ & $1.28(1.21-1.35)^{*}$ & $1.19(1.12-1.26)^{*}$ \\
\hline \multicolumn{5}{|l|}{ Other comorbidities } \\
\hline Anaemia & 35727 (13.54) & $36854(8.63)$ & $1.74(1.65-1.84)^{*}$ & $1.58(1.49-1.68)^{*}$ \\
\hline Psoriasis & $37858(2.17)$ & $38233(1.35)$ & $1.62(1.44-1.82)^{*}$ & $1.53(1.34-1.74)^{*}$ \\
\hline HIV infection & $39099(0.02)$ & $39108(0.02)$ & $2.00(0.60-6.64)$ & $1.84(0.62-5.44)$ \\
\hline
\end{tabular}

hypothyroidism, chronic pulmonary disease, osteoarthritis, depression, anaemia and psoriasis were all significantly higher in patients with incident gout than controls. Furthermore, approximately half of patients with gout had a Charlson index $\geq 1$ within 5 years from initial diagnosis, whereas it took 10 years for half the controls to develop a Charlson index $\geq 1$. Patients with incident gout without a prior history of these comorbidities were more likely than controls to develop cancer, cardiovascular diseases, urolithiasis, renal diseases, DM, hyperlipidaemia, hypothyroidism, peptic ulcer disease, mild liver disease, osteoarthritis, rheumatological disease, depression, anaemia and psoriasis than controls. Despite other diseases which affect longevity, gout itself carried an additional 13\% of deaths in the affected patients. Overall, the burden of comorbidity is very high at diagnosis of gout and the risk of developing new comorbidity is also higher in patients with incident gout than in the general population.

The associations between gout and several categories of comorbidities are well known. For instance, the association between gout and the components of metabolic syndrome is consistently reported ${ }^{38-40}$ and is explained by known inter-relationship between these factors, in part mediated through effects on urate production, renal angiotensin secretion and renal urate excretion. ${ }^{41}{ }^{42}$ However, the association between gout and type $2 \mathrm{DM}$ is more complex. ${ }^{43-45}$ Gout is a risk factor for DM but the risk of DM was not increased in patients with gout at diagnosis. Gout is a known risk factor for cardiovascular diseases such as cerebrovascular disease, ${ }^{46}$ 
congestive heart failure ${ }^{47}$ and myocardial infarction, ${ }^{6}$ 12-14 48 collectively leading to an increased risk for all-cause and cardiovascular mortality in patients with gout. ${ }^{15} 49$ This association may be mediated via endothelial dysfunction caused by high uric acid and low grade crystal-induced inflammation. ${ }^{50}$ Links between hyperuricaemia and kidney disease are wellestablished $^{51-53}$ although convincing data for an aetiological link between gout and chronic kidney disease are sparse. ${ }^{10}$ Although a higher risk of urolithiasis was reported half a century ago ${ }^{5455}$ solid evidence for this emerged only recently 89 and studies using CT identified renal calculi in a third of patients with gout ${ }^{56}$ suggesting underestimation of the magnitude of this risk in studies based solely on a history of symptomatic calculi.

The associations between gout and some or the other comorbidities identified in this study have received less attention. An association between gout and hypothyroidism has been suggested previously in older case series and studies of patients not representative of the general population. ${ }^{18} 1957$ A possible explanation for this association is the ability of thyroid hormone to influence serum urate levels through regulation of glomerular filtration rate. ${ }^{58}$ There is no clear explanation for the association between gout and anaemia, ${ }^{20}$ although hyperuricaemia could result from the increased synthesis of nucleic acids resulting from an erythropoietic response ${ }^{59}$ and conversely greater consumption of non-steroidal anti-inflammatory drugs (NSAID) for joint pain could cause anaemia through gastrointestinal bleeding. Co-localisation of gout and osteoarthritis has been reported previously ${ }^{60}$ and possible explanations for this include reduced viability of chrondrocytes ${ }^{61}$ and mechanical and inflammatory effects of urate crystals on cartilage, and the heightened propensity of damaged cartilage to facilitate monosodium urate crystal nucleation. ${ }^{62}$ Gout is also associated with cancer ${ }^{16} 17$ and psoriasis, ${ }^{63}$ both diseases being associated with increased cell turnover that can cause hyperuricaemia. An association between gout and liver disease is difficult to explain, although a relationship between gout and non-alcoholic fatty liver disease has been suggested previously, ${ }^{64}$ both of which are related to insulin resistance.

In contrast to the positive associations above, neurodegenerative conditions such as dementia and multiple sclerosis seem to have an inverse relationship with incident gout. The association is more apparent prior to presentation with gout than during follow-up analysis. Uric acid has antioxidant effects that particularly may afford a beneficial effect on central neural tissue degeneration ${ }^{65}$ and ageing, ${ }^{66}$ though any such benefit is probably largely outweighed in other tissues due to the deleterious effects of uric acid on vascular endothelium. ${ }^{67}$ Only a few studies have reported that lower urate associates with an elevated risk of multiple sclerosis ${ }^{68}$ but our study supports this. Such negative associations with hyperuricaemia and gout are important in informing the debate concerning the optimum level of urate that we should target in the long term to prevent further crystal formation while avoiding neurological problems from taking the level too low. ${ }^{69}$

The other associations identified in this study between gout and other comorbidities are harder to explain. Previous case reports have suggested that polycythaemia secondary to chronic lung disease might contribute to gout. ${ }^{70}$ In addition, tophi have been found in lung tissue of a patient with interstitial inflammation and pleural effusion. ${ }^{71}$ Patients with HIV infection seem to have a higher risk of gout and this potentially could result from use of antiretroviral agents such as ritonavir which may cause lipodystrophy, metabolic disturbance and hyperuricaemia. ${ }^{72}$
The existence of comorbidity greatly complicates the management of gout and requires special attention in managing patients with gout. Currently, European, ${ }^{21}$ British $^{23}$ and American guidelines $^{22}$ have considered comorbidity as part of initial assessment of patients with gout and the recommended management of chronic hyperuricaemia also partly depends on the existence of comorbidities. However, as our data show, comorbidities with higher absolute and relative risks were not limited to the recommended 'checklist'. Hypothyroidism and anaemia are two examples. Yet screening for thyroid function is not mentioned in any of the guidelines and only the American College of Rheumatology guideline recommends a complete blood cell count for patients with gout, ${ }^{22}$ which is mainly to look for myeloproliferative disease rather than anaemia. Therefore, this study supports the case for a comprehensive investigation for comorbidities, including but not limited to 'checklists', as an integral part of initial assessment for patients with gout at diagnosis. Furthermore, given that half of patients with gout are expected to have one or more comorbidities within 5 years from diagnosis, close observation by annual assessment for the occurrence of incident comorbidity may be warranted.

There are several limitations to this study. First, there may be some misclassification bias since the identification of patients with gout was based on physician diagnosis, rather than according to classification criteria ${ }^{73}$ or to the 'gold standard' of urate crystal identification. However, the validity of gout diagnosis in the CPRD has been investigated and found to be high. ${ }^{32}$ Similarly, there may have been some misclassification of comorbidities though again, most of the comorbidities in this study have been validated previously. ${ }^{28}$ In addition, there is no reason to suspect a differential misclassification between patients with gout and those without. Second, differential ascertainment bias between patients with incident gout and controls cannot be excluded entirely, even though the estimates based on different lengths of previous observations produced similar results. Third, the models did not adjust for all potential risk factors for gouty arthritis, such as diet and physical activity, both of which are not routinely recorded in the CPRD. Fourth, the problem associated with multiple testing may arise in our study. However, this study aimed to provide estimates of disease burden of patients with gout at diagnosis and subsequent to diagnosis, rather than to define causes of gout and the main focus of this analysis was to identify exposures and outcomes that are more closely associated with gout. Also, most of the results were interpreted in the light of existing research so the conclusions are unlikely to have been affected unduly by false-positive findings. In addition, the sample size of this study is about 62000 people. Even when a Bonferroni correction is applied, which is very conservative when the multiple outcome measures under consideration are not independent, the majority of previously significant results remained.

In conclusion, the majority of patients with gout in the UK already have comorbidity at diagnosis and the risk of incident comorbidity continues to rise after diagnosis. All-cause mortality was higher in patients with gout and the increased risk was contributed to by gout itself and by comorbidities to approximately the same degree. This study suggests that a thorough search for a broad range of comorbidity and subsequent vigilant observation should be considered for all patients with gout from the date of first diagnosis.

Contributors C-FK had full access to all of the data in the study and takes responsibility for the integrity of the data and the accuracy of the data analysis. C-FK, WZ and MD conceived and designed the study. C-FK and WZ obtained the 
funding and acquired the data. C-FK, MJG and WZ performed and supervised the statistical analysis. C-FK, MJG, CM, WZ and MD analysed and interpreted the data. C-FK and WZ drafted the manuscript. All authors contributed to the critical revision of the manuscript for important intellectual content. WZ, MJG and MD supervised the study. MD is the guarantor.

Funding This work was funded by the National Science Council of Taiwan (project 103-2314-B-182A-070-MY2) and Chang Gung Memorial Hospital (project CMRPG3A0624) and supported by the University of Nottingham for methodological assistance. The sponsors of the study had no role in design and conduct of the study; collection, management, analysis and interpretation of the data; and preparation, review or approval of the manuscript.

\section{Competing interests None.}

Ethics approval The Independent Scientific Advisory Committee for MHRA Database Research.

Provenance and peer review Not commissioned; externally peer reviewed.

Data sharing Additional data and statistical codes are available on request from the corresponding author at weiya.zhang@nottingham.ac.uk.

Open Access This is an Open Access article distributed in accordance with the Creative Commons Attribution Non Commercial (CC BY-NC 4.0) license, which permits others to distribute, remix, adapt, build upon this work non-commercially, and license their derivative works on different terms, provided the original work is properly cited and the use is non-commercial. See: http://creativecommons.org/ licenses/by-nc/4.0/

\section{REFERENCES}

1 Kuo CF, Grainge MJ, Mallen C, et al. Rising burden of gout in the UK but continuing suboptimal management: a nationwide population study. Ann Rheum Dis 2015;74:661-7.

2 Zhang W, Doherty M, Pascual E, et al. EULAR evidence based recommendations for gout. Part I: Diagnosis. Report of a task force of the Standing Committee for International Clinical Studies Including Therapeutics (ESCISIT). Ann Rheum Dis 2006:65:1301-11.

3 Terkeltaub R. Update on gout: new therapeutic strategies and options. Nat Rev Rheumatol 2010;6:30-8.

4 Kuo CF, Yu KH, See LC, et al. Elevated risk of mortality among gout patients: a comparison with the national population in Taiwan. Joint Bone Spine 2011;78: 577-80.

5 Kuo CF, See LC, Luo SF, et al. Gout: an independent risk factor for all-cause and cardiovascular mortality. Rheumatology (Oxford) 2010;49:141-6.

6 Choi HK, Curhan G. Independent impact of gout on mortality and risk for coronary heart disease. Circulation 2007:116:894-900.

7 Puig JG, Martinez MA. Hyperuricemia, gout and the metabolic syndrome. Curr Opin Rheumatol 2008;20:187-91.

8 Kramer HJ, Choi HK, Atkinson K, et al. The association between gout and nephrolithiasis in men: the health professionals' follow-up study. Kidney Int 2003;64:1022-6

9 Kramer HM, Curhan G. The association between gout and nephrolithiasis: the National Health and Nutrition Examination Survey III, 1988-1994. Am J Kidney Dis 2002;40:37-42.

$10 \mathrm{Yu} \mathrm{KH}$, Kuo CF, Luo SF, et al. Risk of end-stage renal disease associated with gout: a nationwide population study. Arthritis Res Ther 2012;14:R83.

$11 \mathrm{Ab}$. Usbott RD, Brand FN, Kannel WB, et al. Gout and coronary heart disease: the Framingham Study. J Clin Epidemiol 1988;41:237-42.

12 Krishnan $\mathrm{E}$, Baker JF, Furst DE, et al. Gout and the risk of acute myocardial infarction. Arthritis Rheum 2006;54:2688-96.

13 De Vera MA, Rahman MM, Bhole V, et al. Independent impact of gout on the risk of acute myocardial infarction among elderly women: a population-based study. Ann Rheum Dis 2010;69:1162-4.

14 Kuo CF, Yu KH, See LC, et al. Risk of myocardial infarction among patients with gout: a nationwide population-based study. Rheumatology (Oxford) 2013;52:111-17.

15 Clarson L, Chandratre P, Hider S, et al. Increased cardiovascular mortality associated with gout: a systematic review and meta-analysis. Eur J Prev Cardiol 2013 Published Online First: 26 Nov 2013. doi:10.1177/2047487313514895

16 Boffetta P, Nordenvall C, Nyren 0 , et al. A prospective study of gout and cancer. Eur J Cancer Prev 2009:18:127-32.

17 Kuo CF, Luo SF, See LC, et al. Increased risk of cancer among gout patients: a nationwide population study. Joint Bone Spine 2012;79:375-8.

18 Kuzell WC, Schaffarzick RW, Naugler WE, et al. Some observations on 520 gouty patients. J Chronic Dis 1955;2:645-69.

19 Durward WF. Letter: Gout and hypothyroidism in males. Arthritis Rheum 1976;19:123.

20 McAdams-Demarco MA, Maynard JW, Coresh J, et al. Anemia and the onset of gout in a population-based cohort of adults: atherosclerosis risk in Communities study. Arthritis Res Ther 2012;14:R193.
21 Zhang W, Doherty M, Bardin T, et al. EULAR evidence based recommendations for gout. Part II: management. Report of a task force of the EULAR Standing Committee for International Clinical Studies Including Therapeutics (ESCISIT). Ann Rheum Dis 2006:65:1312-24.

22 Khanna D, Fitzgerald JD, Khanna PP, et al. 2012 American College of Rheumatology guidelines for management of gout. Part 1: systematic nonpharmacologic and pharmacologic therapeutic approaches to hyperuricemia. Arthritis Care Res (Hoboken) 2012:64:1431-46.

23 Jordan KM, Cameron JS, Snaith M, et al. British Society for Rheumatology and British Health Professionals in Rheumatology guideline for the management of gout. Rheumatology (Oxford) 2007;46:1372-4

24 Zhu Y, Pandya BJ, Choi HK. Comorbidities of gout and hyperuricemia in the US general population: NHANES 2007-2008. Am J Md 2012;125:679-87.

25 Annemans L, Spaepen E, Gaskin M, et al. Gout in the UK and Germany: prevalence, comorbidities and management in general practice 2000-2005. Ann Rheum Dis 2008;67:960-6.

26 Richette $\mathrm{P}$, Clerson P, Perissin L, et al. Revisiting comorbidities in gout: a cluster analysis. Ann Rheum Dis 2015;74:142-7.

27 Walley T, Mantgani A. The UK General Practice Research Database. Lancet 1997;350:1097-9.

28 Herrett E, Thomas SL, Schoonen WM, et al. Validation and validity of diagnoses in the General Practice Research Database: a systematic review. Br J Clin Pharmacol 2010;69:4-14.

29 Jick H, Jick SS, Derby LE. Validation of information recorded on general practitioner based computerised data resource in the United Kingdom. BMJ 1991;302: 766-8.

30 Khan NF, Harrison SE, Rose PW. Validity of diagnostic coding within the general practice research database: a systematic review. Br J Gen Pract 2010;60:e128-36.

31 Jick SS, Kaye JA, Vasilakis-Scaramozza $C$, et al. Validity of the general practice research database. Pharmacotherapy 2003;23:686-9.

32 Meier $\mathrm{CR}$, Jick $\mathrm{H}$. Omeprazole, other antiulcer drugs and newly diagnosed gout. Br J Clin Pharmacol 1997:44:175-8.

33 Cea Soriano L, Rothenbacher D, Choi HK, et al. Contemporary epidemiology of gout in the UK general population. Arthritis Res Ther 2011;13:R39.

34 Feinstein AR. The pre-therapeutic classification of co-morbidity in chronic disease. J Chronic Dis 1970;23:455-68

35 Charlson M, Szatrowski TP, Peterson J, et al. Validation of a combined comorbidity index. J Clin Epidemiol 1994;47:1245-51.

36 Deyo RA, Cherkin DC, Ciol MA. Adapting a clinical comorbidity index for use with ICD-9-CM administrative databases. J Clin Epidemiol 1992;45:613-19.

37 Khan NF, Perera R, Harper S, et al. Adaptation and validation of the Charlson Index for Read/OXMIS coded databases. BMC Fam Pract 2010;11:1.

38 Choi HK, Ford ES, Li C, et al. Prevalence of the metabolic syndrome in patients with gout: the Third National Health and Nutrition Examination Survey. Arthritis Rheum 2007:57:109-15.

39 Rho YH, Choi SJ, Lee YH, et al. The prevalence of metabolic syndrome in patients with gout: a multicenter study. J Korean Med Sci 2005;20:1029-33.

40 Chen SY, Chen CL, Shen ML. Manifestations of metabolic syndrome associated with male gout in different age strata. Clin Rheumatol 2007;26:1453-7.

41 Rathmann W, Funkhouser E, Dyer AR, et al. Relations of hyperuricemia with the various components of the insulin resistance syndrome in young black and white adults: the CARDIA study. Coronary Artery Risk Development in Young Adults. Ann Epidemiol 1998:8:250-61.

42 Vuorinen-Markkola H, Yki-Jarvinen H. Hyperuricemia and insulin resistance. J Clin Endocrinol Metab 1994;78:25-9.

43 Bhole V, Choi JW, Kim SW, et al. Serum uric acid levels and the risk of type 2 diabetes: a prospective study. Am J Med 2010;123:957-61.

44 Choi HK, De Vera MA, Krishnan E. Gout and the risk of type 2 diabetes among men with a high cardiovascular risk profile. Rheumatology (Oxford) 2008:47:1567-70.

45 Rodriguez G, Soriano LC, Choi HK. Impact of diabetes against the future risk of developing gout. Ann Rheum Dis 2010;69:2090-4.

46 Seminog 00, Goldacre MJ. Gout as a risk factor for myocardial infarction and stroke in England: evidence from record linkage studies. Rheumatology (Oxford) 2013:52:2251-9.

47 Krishnan E. Gout and the risk for incident heart failure and systolic dysfunction. BMJ Open 2012:2:e000282.

48 Abbott RD, Brand FN, Kannel WB, et al. Gout and coronary heart disease: the Framingham Study. J Clin Epidemiol 1988;41:237-42.

49 Lottmann K, Chen X, Schadlich PK. Association between gout and all-cause as well as cardiovascular mortality: a systematic review. Curr Rheumatol Rep 2012;14:195-203.

50 Richette P, Perez-Ruiz F, Doherty M, et al. Improving cardiovascular and renal outcomes in gout: what should we target? Nat Rev Rheumatol 2014;10:654-61.

51 Obermayr RP, Temml C, Knechtelsdorfer M, et al. Predictors of new-onset decline in kidney function in a general middle-European population. Nephrol Dial Transplant 2008:23:1265-73.

52 Obermayr RP, Temml C, Gutjahr G, et al. Elevated uric acid increases the risk for kidney disease. J Am Soc Nephrol 2008;19:2407-13. 
53 Kuo CF, Luo SF, See LC, et al. Hyperuricaemia and accelerated reduction in renal function. Scand J Rheumatol 2011;40:116-21.

54 Yu TF. Nephrolithiasis in patients with gout. Postgrad Med 1978;63:164-70.

$55 \mathrm{Yu}$ T, Gutman AB. Uric acid nephrolithiasis in gout. Predisposing factors. Ann Int Med 1967;67:1133-48.

56 Shimizu T, Hori H. The prevalence of nephrolithiasis in patients with primary gout: a cross-sectional study using helical computed tomography. J Rheumatol 2009:36:1958-62.

57 Erickson AR, Enzenauer RJ, Nordstrom DM, et al. The prevalence of hypothyroidism in gout. Am J Med 1994;97:231-4.

58 Mariani LH, Berns JS. The renal manifestations of thyroid disease. J Am Soc Nephrol 2012:23:22-6.

59 Reynolds MD. Gout and hyperuricemia associated with sickle-cell anemia. Semin Arthritis Rheum 1983;12:404-13.

60 Roddy E, Zhang W, Doherty M. Are joints affected by gout also affected by osteoarthritis? Ann Rheum Dis 2007;66:1374-7.

61 Chhana A, Callon KE, Pool B, et al. The effects of monosodium urate monohydrate crystals on chondrocyte viability and function: implications for development of cartilage damage in gout. J Rheumatol 2013:40:2067-74.

62 Pascual E, Ordonez $S$. Orderly arrayed deposit of urate crystals in gout suggest epitaxial formation. Ann Rheum Dis 1998:57:255.

63 Merola JF, Wu S, Han J, Wu S, et alPsoriasis, psoriatic arthritis and risk of gout in US men and women. Ann Rheum Dis 2015;74:1495-500
64 Kuo CF, Yu KH, Luo SF, et al. Gout and risk of non-alcoholic fatty liver disease. Scand J Rheumatol 2010;39:466-71.

65 Bowman GL, Shannon J, Frei B, et al. Uric acid as a CNS antioxidant. J Alzheimers Dis 2010;19:1331-6.

66 Ames BN, Cathcart R, Schwiers E, et al. Uric acid provides an antioxidant defense in humans against oxidant- and radical-caused aging and cancer: a hypothesis. Proc Natl Acad Sci USA 1981;78:6858-62.

67 Kanellis J, Kang DH. Uric acid as a mediator of endothelial dysfunction, inflammation, and vascular disease. Semin Nephrol 2005;25:39-42.

68 Liu B, Shen Y, Xiao K, et al. Serum uric acid levels in patients with multiple sclerosis: a meta-analysis. Neurol Res 2012;34:163-71.

69 Kuo CF, See LC, Yu KH, et al. Significance of serum uric acid levels on the risk of all-cause and cardiovascular mortality. Rheumatology (Oxford) 2013;52:127-34.

70 Khokhar N. Gouty arthritis in chronic obstructive pulmonary disease. Arch Int Med 1982;142:838.

71 Zang YS, Fang Z, Li B. Gout-associated lung disease. Rheumatology (Oxford) 2012;51:756.

72 Creighton $S$, Miller $\mathrm{R}$, Edwards $\mathrm{S}$, et al. Is ritonavir boosting associated with gout? Int J STD AIDS 2005:16:362-4.

73 Wallace SL, Robinson H, Masi AT, et al. Preliminary criteria for the classification of the acute arthritis of primary gout. Arthritis Rheum 1977;20:895-900.

74 Kellgren JH, Jeffrey MR, Ball J, eds. The epidemiology of chronic rheumatism. Oxford: Blackwell, 1963. 